\title{
Article
}

\section{Reasons for non-suicidal self-harm in adult male offenders with and without borderline personality traits}

Gardner, Kathryn Jane, Dodsworth, Jo and Klonsky, E David Available at http://clok.uclan.ac.uk/13393/

Gardner, Kathryn Jane ORCID: 0000-0003-3904-1638, Dodsworth, Jo and Klonsky, E David (2016) Reasons for non-suicidal self-harm in adult male offenders with and without borderline personality traits. Archives of Suicide Research, 20 (4). pp. 614-634. ISSN 1381-1118

It is advisable to refer to the publisher's version if you intend to cite from the work. http://dx.doi.org/10.1080/13811118.2016.1158683

For more information about UCLan's research in this area go to http://www.uclan.ac.uk/researchgroups/ and search for <name of research Group>.

For information about Research generally at UCLan please go to http://www.uclan.ac.uk/research/

All outputs in CLoK are protected by Intellectual Property Rights law, including Copyright law. Copyright, IPR and Moral Rights for the works on this site are retained by the individual authors and/or other copyright owners. Terms and conditions for use of this material are defined in the policies page.

\section{CLoK}

Central Lancashire online Knowledge www.clok.uclan.ac.uk

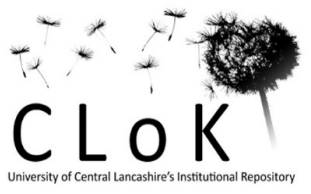


RUNNING HEAD: Reasons for Non-Suicidal Self-Harm in Adult Male Offenders

Reasons for Non-Suicidal Self-Harm in Adult Male Offenders with and without Borderline Personality Traits

Kathryn Jane Gardner ${ }^{2} *$ Jo Dodsworth ${ }^{1}$ E David Klonsky

${ }^{*}$ Corresponding author. Kathryn Jane Gardner. School of Psychology, University of Central Lancashire, Preston, Lancashire, PR1 2HE, UK. KJGardner@uclan.ac.uk

${ }^{2}$ Jo Dodsworth, Psychology Department, HMP Risley, Warrington Road, Risley, WA36BP.

${ }^{3}$ Professor E David Klonsky, University of British Columbia, Department of Psychology, Vancouver Campus, 2136 West Mall, Vancouver, BC Canada V6T $1 Z 4$.

Author's Pre-Print it is advisable to refer to the publisher's version if you intend to cite from the work. 
RUNNING HEAD: Reasons for Non-Suicidal Self-Harm in Adult Male Offenders

\title{
Reasons for Non-Suicidal Self-Harm in Adult Male Offenders with and without Borderline Personality Traits
}

\begin{abstract}
The presented study aimed to advance understanding of the reasons for non-suicidal self-harm (NSSH) in adult male offenders, with and without borderline personality traits. 179 offenders completed self-report measures of NSSH and other clinical constructs, with 42 being identified as having self-harmed. Results were consistent with past research and supported the relative importance of intrapersonal over interpersonal functions, but also highlight that self-harm is performed rarely for one type of reason. The results also show that the presence of borderline personality traits increases the likelihood of endorsing a range of interpersonal reasons. These findings highlight the importance of understanding the range of reasons for engaging in NSSH to help manage the behaviour within the prison
\end{abstract}

Keywords:

Non-suicidal self-harm; self-injury; functions; Borderline Personality Disorder traits; offenders 
RUNNING HEAD: Reasons for Non-Suicidal Self-Harm in Adult Male Offenders

\section{Reasons for Non-Suicidal Self-Harm in Adult Male Offenders with and without Borderline Personality Traits}

\section{The extent and cost of self-harm in prisons}

Self-harm presents a significant challenge within the prison environment and management of the behaviour is a major priority for authorities. In the UK the incidence of self-harm within the prison population is high with some 139,195 self-harm incidents recorded in 26,510 individual offenders in the whole prison estate of England and Wales between 2004 to 2009 (Hawton, Linsell, Adeniji, Sariasla, \& Fazel, 2014). Selfharm is overrepresented in females offenders $-20-24 \%$ relative to $5-6 \%$ of male offenders engaging in self-harm every year (Hawton et al., 2014). The lifetime prevalence of self-harm in UK prison settings is also high for both females (up to 51\%; Borrill et al., 2003; Vollm \& Dolan, 2009) and males (17\%; Maden, Chamberlain \& Gunn, 2000), and suggests that many offenders begin self-harm before coming to prison. Recent Government statistics confirm these worrying trends, with some 25,755 incidents of self-harm in 2014 alone (Ministry of Justice, 2015). Both female and male incidents of self-harm in prisons increased by around 10\% between 2013 and 2014, and the number of males and females self-harming also increased some $10 \%$ and $6 \%$, respectively. However, while incidents of female self-harm in prison fell between 2010 and 2013 for females, rates for males have continued to rise steadily each year. Moreover, despite females accounting for a disproportionate number of self-harm incidents in prisons, females make up only $5 \%$ of the UK prison population (Ministry of Justice, 2015). Male self-harm thus presents a significant problem for the prison service.

The personal cost of self-harm is evident, as it is associated with increased psychological distress and suicidal feelings (e.g., Lohner and Konrad, 2006), suicidal behaviour (Hamza, Stewart \& Willoughby, 2012) and a high risk of completed suicide 
RUNNING HEAD: Reasons for Non-Suicidal Self-Harm in Adult Male Offenders

(Hawton et al., 2014). Within the prison environment self-harm is especially costly and puts a significant strain on service resources. Not surprisingly, staff report feeling increased frustration and powerlessness (Marzano, Adler \& Ciclitira, 2013), and often hold negative, dismissive and hostile attitudes towards offenders (e.g., Knowles, Townsend \& Anderson, 2013; Marzano, Ciclitira, \& Adler, 2012). This costly nature of self-harm combined with the larger male prison population, means that understanding and treating self-harm in male offenders is a priority.

\section{The Nature and Functions of Non-Suicidal Self-Harm}

Underpinning any attempt to assess and manage offenders at risk of self-harm should be an understanding of the functions that self-harm serves. This field has seen an explosion of research over the last decade, but conceptual and terminological disparities hamper attempts to review and aggregate the literature. In particular, there is dispute about the importance of distinguishing non-suicidal from suicidal forms. Some researchers in the UK use the term self-harm to refer to deliberate self-injury and selfpoisoning (through either illicit or prescribed substances), regardless of intent (e.g., Madge et al., 2008). Thus, self-harm includes: i) methods that directly damage the skin (e.g., cutting, scratching/carving, and biting or hitting oneself), as well as less direct methods where the damage is likely to be internal (e.g., self-poisoning); and ii) suicidal as well as non-suicidal intentions. The inclusion of self-poisoning is justified because the behaviour is often performed in the absence of suicidal intent (Kapur et al., 2006), and can have near-immediate damaging internal effects.

Many other researchers in the UK (e.g., Mars et al., 2014), Europe (e.g., Brunner et al., 2013; Groschwitz et al., 2015), the USA (e.g., Nock, 2010; Klonsky, May \& Glenn, 2013) and other countries distinguish clearly between suicidal and non-suicidal self-harm. In the USA the term "self-harm" is typically synonymous with "self- 
RUNNING HEAD: Reasons for Non-Suicidal Self-Harm in Adult Male Offenders

injurious behaviours" and denotes a broad spectrum of behaviours ranging from indirectly self-damaging behaviours such as smoking and alcohol abuse, to "nonsuicidal self-injury" (NSSI) and suicidal behaviours which are seen as distinct but related phenomena (Bentley, Nock \& Barlow, 2014; Nock, 2010). NSSI was recently included within the DSM-5 (APA, 2013) as a condition requiring further study, and refers to attempts to deliberately and directly hurt one's body in some way in the absence of suicidal intent (APA, 2013; Klonsky \& Glenn, 2009; Nock, 2008). NSSI is direct in terms of the directness of the act and the immediate consequences that occur. In the review below, we use the terms self-harm, but revert to NSSI when reviewing studies or theories that have focused specifically on non-suicidal self-injury (for discussion of the approaches to defining and conceptualising self-harm see Lohner and Konrad, 2007).

The reasons that motivate people to engage in self-harm can be broadly categorised into two superordinate domains: intrapersonal/automatic functions such as affect regulation, and interpersonal/social functions such as to communicate one's pain to others (Klonsky \& Glenn, 2009). Nock and Prinstein (2004) have further broken this down into intra and inter-personal functions where the behaviour functions to provide either positive or negative reinforcement; the former involves the presentation of a favourable stimulus, whilst the latter involves the removal of an aversive stimulus. Intrapersonal reasons for NSSI are typically endorsed to a greater degree than social ones (e.g., Nock \& Prinstein, 2004; Klonsky, 2009), and the relative importance of intrapersonal functions has been demonstrated in numerous studies. For example, intrapersonal functions predict unique variance in lifetime NSSI frequency above and beyond that explained by interpersonal functions (Saraff \& Pepper, 2014), and conclusions from a review of 18 studies found that affect regulation was by far the most 
RUNNING HEAD: Reasons for Non-Suicidal Self-Harm in Adult Male Offenders

common function for NSSI (Klonsky, 2007). Specifically, NSSI is preceded often by negative affect, reduces negative affect, and is most commonly driven by the need to reduce negative affect. However, many of the studies reviewed deliberately set out to investigate affect regulation accounts of self-harm; fewer studies provided a more balanced-view by investigating both intrapersonal and interpersonal functions that often coexist simultaneously (e.g., Scoliers et al., 2008). Moreover, psychiatric and adolescent populations are overrepresented in the studies reviewed. As the base rate for particular functions will vary according to the sample type and environment, it is important to base conclusions about the functions of self-harm on research using the sample of interest.

A small handful of studies have explored the intrapersonal and interpersonal functions of self-harm within forensic populations and arrived at the same conclusion: according to a review of 11 studies, intrapersonal functions such as affect regulation dominate (Dixon-Gordon, Harrison \& Roesch, 2012). The studies reviewed by DixonGordon et al., used a variety of different sample types (male and female, young and adult offenders) and definitions of self-harm, with some studies not separating the suicidal from non-suicidal form of the behaviour. In terms of methodology, the majority were qualitative $(n=6)$, thus providing depth of understanding of functions. Other studies include a study that used just 4 questions to assess the frequency of specific motives (e.g., to spite your lover or parents" (in a Greek sample); two retrospective reviews of self-harm incidents or discharge summaries; and two studies focused on topics that did not explicitly examine functions (i.e., studies on antecedents/consequences, or on the psychophysiology of self-harm). Four published studies not included in this review employed either a case study or qualitative methods (Bennett \& Moss, 2013; Jeglic et al, 2005), or a brief self-report measure that assesses a 
RUNNING HEAD: Reasons for Non-Suicidal Self-Harm in Adult Male Offenders

limited number of functions in young offenders (Penn, Knowles, Townsend \& Anderson, 2011). In sum, these quantitative studies have not provided sufficient breadth of understanding of the range of functions of self-harm; use of a comprehensive standardised measure such as the Inventory of Statements about Self-Injury (Klonsky, 2007) would address this gap. The relative importance of intrapersonal functions is almost certainly likely to be supported even with the use of such measures. Nonetheless, a more balanced view of intra- and interpersonal functions is necessary, not least because: a) many individuals endorse multiple intra- and interpersonal functions simultaneously (Klonsky, 2009); and b) interpersonal functions should be acknowledged and understood. The latter is important because staff working with offenders often overestimate interpersonal functions such as "to gain attention", and perceive these to be manipulative and controllable reasons for self-harm (Pannell, Howells, \& Day, 2003; Kenning et al., 2010; Knowles et al., 2013). Thus, it seems that interpersonal motivated self-harm is acknowledged by staff, yet it is poorly understood. In further support of this, there is some evidence that interpersonally motivated selfharm is not perceived to be a 'genuine' reason, and nor does it represent psychological distress or a risk of suicide (Knowles et al., 2013; Kenning et al., 2010; Short, Cooper, Shaw, Kenning, Abel \& Chew-Graham, 2009). This is in spite of evidence that many offenders who self-report perceived manipulative functions such as 'to obtain a transfer', are simultaneously high in suicidal intent (Dear, Thomson \& Hills, 2000). Staff training is an important component of the management of self-harm in prisons (Humber, Hayes, Senior, Fahy \& Shaw, 2011), but due consideration needs also to be given to the sources of variation in self-harm functions. In particular, dispositional vulnerability factors that are prevalent in offenders, such as personality disorder traits, may increase the likelihood that an individual self-harms for a particular reason. 
RUNNING HEAD: Reasons for Non-Suicidal Self-Harm in Adult Male Offenders

\section{Borderline Personality Traits as a Source of Variation in Non-Suicidal Self-Harm}

\section{Functions}

Offenders with personality disorders are a group of individuals within which the rate of self-harm is high, with up to $61.4 \%$ reporting at least one incident of self-harm (Mannion, 2009). Self-harm features most commonly in borderline personality disorder and is one of the DSM-5 criteria for the disorder (APA, 2013). In the UK the prevalence of BPD in prison populations is high between 25-50\% (Sansone \& Sansone, 2009). The percentage of men with BPD is much lower than for women (e.g., 26.8\% versus $54.5 \%$, respectively; Black et al., 2007) and this mirrors the pattern of prevalence rates of selfharm in prisons. However, these figures are much higher than for community samples where only 1 to $6 \%$ of adults have BPD (Coid, Yang, Tyrer, Roberts \& Ullrich, 2006; Zanarini et al., 2011).

Borderline personality disorder is conceptualised as a disorder of emotion dysregulation (Linehan, 1993), and many of the behaviours exhibited by those with BPD (e.g., self-harm and impulsive substance taking) typically result from either attempts to regulate emotion or emotion dysregulation (Linehan, 1993). These affective difficulties occur within the context of unstable and intense relationships, with the individual experiencing significant interpersonal distress, abandonment and/or rejection fears (DSM-5; APA, 2013), and difficulties with attachment (Agrawal, Gunderson, Holmes, \& Lyons-Ruth, 2004). Research in offender populations is limited but evidence suggests that BPD traits predict both NSSI and suicidal behaviours (Gardner, Dodsworth, \& Selby, 2014, using the same sample as this study: $\mathrm{N}=179$ ), and that offenders with BPD report a positive emotional shift following NSSI (Chapman \& Dixon-Gordon, 2007). This affect regulatory function of self-harmers BPD is supported throughout a range of other sample types and methods, with interpersonal motivations 
RUNNING HEAD: Reasons for Non-Suicidal Self-Harm in Adult Male Offenders

for NSSI being endorsed significantly less frequently (Brown, Comtois \& Linehan, 2002; Kleindienst et al., 2008). The same pattern has emerged in studies using the comprehensive Inventory of Statements about Self- injury (Bracken-Minor \& McDevittMurphy, 2014; Klonsky \& Glenn, 2009; Sadeh et al., 2014).

Ultimately, we argue that the presence of BPD traits in male offenders will influence the reasons why offenders engage in self-harm. This argument is partially supported by a recent study using the ISAS (Klonsky \& Glenn, 2009) that found that self-harmers with BPD traits were significantly more likely to engage in the behaviour for self-punishment, to end the experience of dissociation, and to avoid the impulse to commit suicide (three intrapersonal functions: Bracken-Minor \& McDevitt-Murphy, 2014). Yet, the study used a predominantly female (80\%) student sample and controlled gender when examining differences between several BPD/NSSI groups on NSSI functions, an approach that removes real construct variance from and thus distorts the BPD/NSSI variable (see Miller \& Chapman, 2001, for discussion). We argue that interpersonal difficulties and distress may increase the likelihood of self-harming for interpersonal reasons, relative to individuals without BPD traits. Moreover, in addition to traits such as BPD explaining offenders' self-harm motivations in general, offenders may differ in their motivations as a direct result of constraints of the prison environment. Specifically, interpersonal reasons may be endorsed more frequently in prison samples where the restrictive prison environment means that attachment needs are not fulfilled which is crucial for those with BPD traits (Agrawal, Gunderson, Holmes, \& Lyons-Ruth, 2004; Fonagy, Target, Gergely, Allen, \& Bateman, 2003). This may be even more likely in male offenders with BPD traits given evidence of an increased incidence of interpersonal functions in males relative to females (e.g., Claes, Vandereycken \& Vertommen, 2007, using an adolescent sample). Yet, the stigma 
RUNNING HEAD: Reasons for Non-Suicidal Self-Harm in Adult Male Offenders

around self-harm as a predominantly feminine behaviour (see Chandler, Myers \& Platt, 2011, for discussion) may reduce the likelihood of males' disclosing or revealing their self-harm to others. Further research comparing the full range of specific reasons for self-harm within male offenders with and without BPD traits is needed to advance our understanding of these issues.

\section{Rationale, Aims and Objectives}

The reduction of self-harm is an important objective for the prison service, and staff training that raises awareness and understanding of the reasons that drive self-harm is integral to managing the behaviour. Indeed, understanding the function of self-harm is equally as important as the behaviour itself. The primary aim of this study was to advance our understanding of the broad range of reasons for self-harm in adult male offenders, with and without borderline personality traits i.e., traits that are consistent a diagnosis of BPD. In light of the somewhat restricted approach to conceptualisation and measurement of self-harm functions (which has often been biased towards assessing intrapersonal functions), we provided a comprehensive and balanced assessment of functions through use of the Inventory of Statements about Self-Injury (ISAS: Klonsky \& Glenn, 2009). This allowed us to obtain a more complete picture of the range of selfharm functions in adult male offenders with low and high BPD traits, and interpret these within the context of an empirically supported theoretical model of self-harm functions.

In this paper we define self-harm as any deliberate self-injurious behaviour that does not involve suicidal intent, irrespective of degree of lethality. Thus, the definition includes direct methods of self-injury vis-à-vis the skin and body, and self-poisoning. We refer to this as non-suicidal self-harm (NSSH) henceforth. The term itself is not important, but this definition is because it distinguishes NSSH from suicide and these are distinct but related phenomena (for review see Hamza et al., 2012). Moreover, this 
RUNNING HEAD: Reasons for Non-Suicidal Self-Harm in Adult Male Offenders

definition captures the full range of clinically severe and less severe NSSH behaviours. There were four objectives of this study:

(1) to identify, using an established and comprehensive psychometric measure, the frequency of both broad (i.e., scale level) and specific reasons for NSSH within adult male offenders;

(2) to identify whether the multiple reasons endorsed by participants reside predominantly in just the intrapersonal or interpersonal domain, or both;

(3) to examine whether the endorsement of intrapersonal and interpersonal functions differ for individuals with and without borderline personality traits;

(4) to test the hypothesis that the most frequently endorsed specific reason for self-harm in participants with BPD traits falls within the realms of affect regulation, based on the emotion dysregulation theory of BPD (Linehan, 1999);

\section{Method}

\section{Participants and Procedure}

Participants were 179 adult male offenders $(M$ age $=37.70, S D=13.53$, Range $=$ 21-77) detained in Category $\mathrm{C}$ (medium-secure) prisons in the UK, recruited during a period of lock down when offenders were in their cells. The researcher approached participants by knocking on cell doors and providing a brief verbal explanation (the verbal explanation referred to a study on specific behaviours and traits within the prison, rather than to self-harm specifically), and subsequently the questionnaire booklet if the participant was interested. The majority of offenders serving determinate sentences had been in prison for between 1 and 10 years $(68.2 \%)$, with a small minority being detained for less than 12 months (3.4\%) or more than 10 years $(4 \%)$; $24.4 \%$ were serving indeterminate life sentences. Regarding offence type, largest percentages were for sexual (35.7\%), acquisitive (26.9\%) and violent (non-fatal) offences (15.2\%), 
RUNNING HEAD: Reasons for Non-Suicidal Self-Harm in Adult Male Offenders

followed by possession of drugs (9.9\%), murder/manslaughter (5.8\%), arson/attempted arson (4.7\%) and fraud (1.8\%). Of the 179 offenders, $42(23.5 \%)$ had engaged in lifetime NSSH. Ethical approval was provided by the University, and a prison ethics application was approved to undertake research in Her Majesty's Prison Service.

\section{Materials}

The Inventory of statements about self-injury (ISAS; Klonsky \& Glenn, 2009) comprises two sections which measure (1) the frequency of a range of NSSH behaviours over the person's lifetime, including cutting, biting, burning, carving, pinching, pulling hair, sever scratching, banging or hitting, interfering with wounds, rubbing skin against rough surfaces, sticking self with needles, and swallowing dangerous substances; and (2) the function of NSSH. We summed the frequencies for each behaviour to calculate the lifetime frequency of NSSH. Internal consistency in this sample was .70 for the 12 self-harm behaviours. It is worth noting that including selfpoisoning and the less severe yet typically compulsive "hair pulling" have not inflated the prevalence of NSSH in this study: of those who endorsed "self-poisoning" or "hair pulling", only three did not endorse another NSSH behaviour.

Participants only completed the second section of the ISAS if they had reported having engaged in NSSH within section one. Functions were rated on 3-point Likert scale (from $0=$ not relevant at all, to $2=$ very relevant) using 39 statements. Thus, a score of 1 or more indicates endorsement of the function. The ISAS is a reliable and valid measure of NSSH in other samples (e.g., Klonsky \& Glenn, 2009) but has yet to be examiner in an offender sample.

Items from the Personality Diagnostic Questionnaire $4^{\text {th }}$ Edition (PDQ-4; Hyler, 1994) were used to BPD traits (9 items). The PDQ-4 is a false/true (0/1) self-report questionnaire based on the DSM-IV criteria and can thus determine the presence or 
RUNNING HEAD: Reasons for Non-Suicidal Self-Harm in Adult Male Offenders

absence of personality disorder traits that are consistent with a DSM-IV diagnosis (APA, 2000). The PDQ-4-BPD scale has good psychometric properties in nonclinical samples (Gardner \& Qualter, 2009) and has also been used in prison samples (Blackburn, Donnelly, Logan, Stanley, \& Renwick, 2004). A cut-score of $>5$ is used to indicate the presence or absence of BPD traits. To obtain information about sample characteristics items from the remaining cluster B personality disorder subscales were also administered: Anti-social (8 items), Narcissistic (9 items) and Histrionic (8 items) personality disorder. Internal consistencies (Cronbach's alpha) in this sample were: .71 (BPD), .74 (APD), .61 (NPD), .24 (HPD). Note that likelihood of obtaining statistically significant effects with the HPD variable are low given the alpha of .24.

To obtain information about the sample characteristics, suicidal behaviours and depression were also assessed. The Suicide Behaviours Questionnaire-Revised (SBQ-R; Osman et al., 2001) was used to measure suicidal behaviours. The measure uses four items to assess suicidality: (1) lifetime suicide ideation and/or suicide attempt, (2) frequency of suicidal ideation over the past twelve months, (3) threat of suicide attempt, and (4) self-reported likelihood of suicidal behaviour in the future, but item 4 not used due to concerns about disclosure of future suicides within the prison environment. This measure has acceptable internal consistency reliability (alpha) estimates (Osman, et. al, 2001). In this sample, Cronbachs alpha was .73.

The Center for Epidemiologic Studies Depression Scale (CES-D; Radloff, 1977) includes 20 items responded to in relation to the past week, and rated on a 4-point Likert-type scale (from $0=$ rarely or none of the time, to $3=$ most or all of the time). The CES-D has good internal consistency and adequate test-retest reliability (Radloff, 1977). Internal consistency in this sample was .80.

\section{Results}


RUNNING HEAD: Reasons for Non-Suicidal Self-Harm in Adult Male Offenders

\section{Sample Characteristics}

Characteristics of offenders are shown in Table 1. As expected, the NSSH group were significantly more likely to have spent time being monitored for self-harm and suicide and were also significantly higher on self-reported suicidal behaviours and depression. 32 offenders (17.9\% of the whole sample) met the criteria for BPD traits. The NSSH group was significantly more likely to include offenders high on BPD traits ( $n=20$ or $47.6 \%$ of the NSSH group), compared with the non-NSSH group $(n=12$, or $8.8 \%$ of the total non-NSSH group). ). In contrast, the NSSH group were significantly less likely to be high on antisocial personality traits. Notably, the prevalence of offenders with BPD traits is lower than studies using similar populations and BPD screening measures (e.g., 26.8\% using a 9-item BPD screening interview and a prison sample, Black et al., 2007; and $31 \%$ in a sample of personality disordered offenders in a high secure setting).

\section{INSERT TABLE 1 HERE}

\section{Frequency of NSSH}

42 offenders had engaged in lifetime NSSH. Table 2 shows the percentage of self-harming offenders who use different NSSH behaviours. The more clinically severe (i.e., cutting, banging, dangerous substances) were most frequently endorsed. $28.6 \%$ engaged in just one method (excluding the "other" category), with the majority (50\%) using between 2 and 4 methods. Similar to previous studies of offenders with personality disorders (e.g., Mannion, 2009), the most frequently endorsed method was cutting. Offenders in the high BPD trait group were significantly more likely to use a 
RUNNING HEAD: Reasons for Non-Suicidal Self-Harm in Adult Male Offenders

range of other methods, including banging, wound interference, curbing skin, carving and swallowing dangerous substances (i.e., self-poisoning).

The descriptive statistics show that that the frequency of lifetime NSSH incidents ranged from 1 to 4,000 separate acts in the whole NSSH group. In the low BPD trait group, the mode was 1 which may reflect individuals who have harmed themselves once versus repeatedly. The mode for the high BPD trait group suggests that for most there may have been multiple episodes of self-harm ${ }^{1}$.

\section{INSERT TABLE 2 HERE}

\section{Preliminary Analyses}

The functions of NSSH were examined for the 42 offenders who reported having engaged in NSSH. Missing data were present across some ISAS functions, but as this was only a few cases pairwise deletion was used. Thus, for some analyses there were less than 42 participants. We reduced in size, one extreme univariate outlier on the Interpersonal scale of the ISAS.

Table 3 shows the means, standard deviations and alpha values for the various functions. Cronbach's alphas ranged from .54 to .88 , with the majority being above .70 . The mean total score on the ISAS functions scale was $14.17(S D=15.22)$, which was similar to the mean score previously found in a student sample by Klonsky and Glenn (2009). Also, as expected the scaled mean for the Intrapersonal factor $(M=.57, S D=$ $.55)$ was significantly higher $(t=(39) 6.36, p<.001)$ than for Interpersonal factor $(M=$ $.23, S D=.30)$. We then compared mean scores for each of the 13 scales to those reported in a non-detained sample of 235 participants (Klonsky \& Glenn, 2009). Using the Welch-Satterthwaite test for independent samples with unequal variances, only the anti- 
RUNNING HEAD: Reasons for Non-Suicidal Self-Harm in Adult Male Offenders

suicide function was significantly different between the two samples, with male offenders scoring significantly higher than the student sample. Note that Peer Bonding, Revenge and Sensation Seeking could not be analysed due to insufficient variability in the data, suggesting low endorsement of these three interpersonal functions. All three variables were excluded from further analysis.

In sum, the patterns of means is highly similar to previous research, but three of the twelve functions scales were endorsed by few participants. Taking this into account, and to reduce the number of analyses, only the 39 items and two superordinate factors were used in subsequent analyses.

\section{INSERT TABLE 3 HERE}

\section{Functions of NSSH}

To address the first objective, we first examined the number and type of reasons for self-harm. Analyses were conducted at the item $(n=39$ ISAS reasons) and factor level ( $\mathrm{n}=2$ Intra- and Interpersonal factors). The 39 reasons for self-harm are shown in Table 4, along with the percentage of participants engaging in NSSH who endorsed each reason (a reason was identified as "endorsed" if it had been rated between 1-3 and "not endorsed" if rated 0 by the participant). For descriptive purposes, the Table shows which of the 13 functions the item corresponds to. In total, there are 15 intrapersonal items and 24 interpersonal ones.

INSERT TABLE 4 HERE 
RUNNING HEAD: Reasons for Non-Suicidal Self-Harm in Adult Male Offenders

Out of the 39 reasons, an average of $9.56(S D=8.42)$ were endorsed overall, although the standard deviation shows there is considerable variation in the number of reasons endorsed. On average, there were more intrapersonal reasons endorsed: scaled $M=.57(S D=.55)$ compared to $M=.23(S D=.30)$ for interpersonal reasons. $82.9 \%$ of participants endorsed a reason that was intrapersonal in nature, and 72.5\% interpersonal. Finally, as shown in Table 4, all 39 items were endorsed by at least one participant.

Regarding the types of reasons, the five most frequently endorsed reasons were of an intrapersonal nature and from the affect regulation ("releasing emotional pressure", "reducing anxiety, frustration and anger") and self-punishment scales (“punishing myself", "expressing anger towards myself", and "reacting to feeling unhappy or disgusted with myself"). Note that the five most frequently endorsed 'Interpersonal' items belonged to a range of different scales: interpersonal boundaries ("creating a boundary between myself and others"); interpersonal influence ("letting others know the extent of my emotional pain", "seeking care or help from others"); selfcare ("creating a physical injury that is easier to care for"); and toughness ("seeing if I can stand the pain").

To address the second objective, we used the 39 reasons and found that the number of participants endorsing reasons that are just intrapersonal, interpersonal, or both were $17.1 \%, 2.9 \%$ and $80.0 \%$, respectively.

\section{Functions of NSSH in Offenders with Low versus High BPD Traits}

To address the third objective, we examined the percentage of offenders endorsing each item within both low and high BPD trait groups. An average of 3.00 (SD $=3.36)$ and $7.85(S D=4.18)$ out of 15 intrapersonal items were endorsed in the low and high BPD groups, respectively: $t(39)=-4.10, p<.001$. This same pattern emerged for interpersonal functions, where the high BPD traits group endorsed an average of 6.10 
RUNNING HEAD: Reasons for Non-Suicidal Self-Harm in Adult Male Offenders

$(S D=4.89)$ out of 24 functions, compared to $1.55(S D=2.21)$ for the low BPD traits group: $t(38)=-3.79, p<.001)$. Thus, those with high BPD traits endorse a broader range of both intrapersonal and interpersonal functions. We further investigated this potential relationship between BPD and intrapersonal and interpersonal functions using correlations and found no significant difference in the strength of the relationship between the dichotomous BPD traits variable and the Intrapersonal $(r=.55, p<.01)$ and Interpersonal $(r=.50, p<.01)$ factors (Hotelling's $t^{2}(37)=.63, p>.05$, two-tailed). The strength of these correlations increases to $r=.69$ for both factors when correlated with a continuous BPD variable. Note that all of these effects remain significant when controlling for NSSH frequency, suggesting that the differences are not accounted for by the higher self-harm in the high BPD group.

In the low BPD group, reasons belonging to the Intrapersonal factor were endorsed by $66.7 \%$ of participants, compared to $50.0 \%$ for the Interpersonal factor; in the high BPD traits group these figures were $100.0 \%$ and 95.0 , respectively.

Finally, as shown in Table 4, in both low and high BPD groups all 15 intrapersonal reasons were endorsed by at least one participant. However, in the low BPD group 10 of the 24 interpersonal reasons were not endorsed at all, relative to all 24 items in the high BPD group. We then used chi-square analyses to identify significant differences between the two groups in terms of the percentage of self-harmers endorsing of each reason. As shown, there were significant effects for 19 of the 39 reasons, with a significantly higher percentage of BPD participants endorsing all 19 reasons. Eleven of these were intrapersonal in nature (out of a possible 15 intrapersonal reasons: $73 \%$ ), suggesting that the high BPD group are significantly more likely to endorse a range of reasons relating to anti-dissociation, anti-suicide, distress and self-punishment. 
RUNNING HEAD: Reasons for Non-Suicidal Self-Harm in Adult Male Offenders

Eight reasons (out of a possible 24: $33 \%$ ) endorsed by significantly more of the high BPD group were interpersonal in nature. These reasons related to autonomy, interpersonal boundaries, interpersonal influence, self-care, sensation seeking, and toughness; items relating to revenge or peer bonding were not endorsed to a significantly higher extent.

Effect sizes $(\varphi)$ typically ranged from small (.10) to large (.50), with an average effect size .31 , or .37 or .28 for intra versus interpersonal reasons, respectively.

To address the hypothesis that the most frequently endorsed specific reason for NSSH in participants with BPD traits is an affect regulation reason, we identified the five most frequently endorsed reasons and found them to be intrapersonal. Within the low BPD group, the most frequently endorsed were the same reasons with one exception: "causing pain so I will stop feeling numb" was endorsed less frequently. The most frequently endorsed reason in the high BPD as well as low BPD and whole NSSH sample was "releasing emotional pressure that has built up inside of me".

Finally, it is possible that offenders with BPD traits who self-harm are more clinically severe overall, and if this is the case, group differences in the functions of self-harm could be due to general psychopathology rather than BPD traits. To explore this, a series of 2 (self-harm group) x 2 (BPD group) between subjects factorial ANOVAs were conducted using either HPD, NPD, APD, depression or suicidal behaviours as dependent variables. To summarise these findings, we did not find evidence to support the notion that our NSSH with BPD traits group was more clinically severe overall; the group scored significantly higher on only suicidal behaviour (due to space constraints these analyses are not reported here but are available upon request from the first author).

\section{Discussion}


RUNNING HEAD: Reasons for Non-Suicidal Self-Harm in Adult Male Offenders

This study aimed to understand the specific reasons for non-suicidal self-harm (NSSH) within a group of detained adult male offenders, with and without borderline personality traits. In this sample, $24 \%$ reported a history of NSSH and the majority reported having engaged in the more clinically severe forms such as cutting and swallowing dangerous substances. These individuals were distinguishable from nonNSSH offenders in terms of high BPD traits, increased suicidal behaviours and depression, and lower antisocial personality disorder traits. Thus, the NSSH group reported more emotional disturbance than offenders who do not self-harm.

To achieve our aim, we used a comprehensive measure of NSSH functions. Results showed that the ISAS is a reliable measure in a male offender population and produces comparable data to non-detained individuals (Klonsky \& Glenn, 2009). There were some notable exceptions, including moderate reliabilities for some functions and insufficient variability for the peer bonding, revenge and sensation seeking functions. This low endorsement is interesting in and of itself, and could suggest that self-harm does not serve these functions in this population. The desire to "fit in with others" for example (peer bonding), may be less likely in a male sample where self-harm due to fear of stigma because self-harm is perceived to be a feminine behaviour (see Chandler, Myers \& Platt, 2011, for discussion). Alternatively, it is possible that this small sample of self-harmers failed to capture many individuals with the specific characteristics that make them vulnerable to self-harming for interpersonal reasons. Indeed, there is evidence that the need to self-harm for intra- relative to interpersonal reasons is driven by the affective and not behavioural or interpersonal features of BPD (Sadeh et al., 2014), and the presence of these features can vary massively between samples due heterogeneity of the disorder. Interestingly though, at the item level it was clear that at 
RUNNING HEAD: Reasons for Non-Suicidal Self-Harm in Adult Male Offenders

least one person endorsed each of the three items within each subscale, highlighting the relevance of these functions for some individuals.

In relation to our first and second objectives, the reasons for NSSH were broad and it was clear that in the vast majority of cases, offenders endorsed multiple specific intrapersonal and interpersonal reasons; this is consistent with past studies using student samples (e.g., Klonsky, 2009). These findings, along with the preference for intrapersonal reasons, are a challenge to prison staff who overestimate the interpersonally motivated reasons for self-harm (e.g., Kenning et al., 2010; Knowles et al., 2013). However, although less frequently endorsed by offenders, interpersonal reasons for self-harm are equally as present in offenders as they are in student populations (e.g., Klonsky \& Glenn, 2009). One exception was the anti-suicide function, suggesting that offenders used self-harm more to stop suicidal thoughts.

In relation to the third objective, interestingly BPD traits was not correlated more strongly with the broadly conceptualised intra- relative to interpersonal factor, unlike in a student sample (Klonsky \& Glenn, 2009). However, identifying the number of offenders endorsing individual reasons enabled us to identify important and more specific differences between offenders with low and high BPD traits. It was clear that the latter group endorsed a broader range of interpersonal reasons, suggesting the presence of within group differences. In particular, those with high BPD traits were significantly more likely to self-harm to establish autonomy, manage boundaries between themselves and others, influence others, create sensation, demonstrate toughness, and for self-care. Moreover, all but one participant in the high BPD group endorsed at least one interpersonal reason, compared to only half of the low BPD group. These differences may reflect the interpersonal difficulties that characterise BPD and which manifest through socially reinforcing self-harm. In this sense, self-harm serves to 
RUNNING HEAD: Reasons for Non-Suicidal Self-Harm in Adult Male Offenders

influence and communicate with others, probably because other methods have failed (Nock, 2008). However, it should be noted that these are item-level analyses and not all items relating to these concepts were endorsed to a significantly greater extent than the high BPD trait group. It is also worth noting that not all who self-harmed in this study were high on BPD traits, supporting the separateness of self-harm from BPD and being consistent with the notion of an "NSSI disorder" (APA, 2013).

In support of the hypothesis, the most frequently endorsed specific reasons in this sample and in those with high BPD traits were affect regulatory in nature. These results are consistent with previous research (e.g., Klonsky \& Glenn, 2009; Sadeh et al., 2014) and theory (Linehan, 1999). However, the findings herein and heterogeneity of BPD reminds us that self-harm is often performed for a range of individual reasons, and is not always driven by affect.

There are limitations to this study that warrant attention. First, we adopted a definition of self-harm that considered intent, focusing only on non-suicidal self-harm. It is possible though, that offenders were not fully aware of their intentions, possess ambiguous intentions, or provide socially desirable responses (e.g., claiming that their self-harm is non-suicidal instead of suicidal).

Second, the study focused on lifetime self-harm rather than self-harm within the prison because our interest was in the stable personality traits of this sample (which are likely to have been present prior to incarceration as they develop in early adolescence/early adulthood e.g., Becker, Grilo, Edell \& McGlashan, 2002), that might explain the endorsement of specific functions. As a result, generalisation of the findings to a specific observation period (e.g., 1-month prevalence, or past 12 months) either in our outside of the prison is not possible, and it means that we cannot be sure whether some self-harm occurred prior to criminal activity. Isolating prevalence to a specific 
RUNNING HEAD: Reasons for Non-Suicidal Self-Harm in Adult Male Offenders

period of interest would ascertain whether specific functions of NSSH are more prevalent within the constraints of the prison environment. For example, interpersonal functions may be more prevalent as a means of eliciting care within a restrictive environment where attachment needs - which are central to the development of BPD traits (Agrawal et al., 2004; Fonagy, Target, Gergely, Allen, \& Bateman, 2003) - are not fulfilled. However, previous research with youths in custody has shown that some $75 \%$ of lifetime self-harm began in prison, and this may have been the case in our sample (Kenny, Lennings \& Munn, 2008).

Third, although we recruited a relatively large number of offenders, the number self-harming was relatively small; this may have reduced the variation in the reasons endorsed. In addition, given the small sample combined with the exploratory nature of the study, we chose not to use a more conservative alpha level when interpreting the results of multiple tests because this would have led to a reduction in statistical power. Our study was powerful enough to detect large effect sizes, but some results were only just statistically significant and these would have been missed with a more stringent alpha level. This highlights the importance of replicating the findings with a larger sample.

Future research should address these limitations but also explore functions in distinct subgroups of self-harmers. Specifically, offenders who began their NSSH before vs. in prison may represent distinct subgroups of self-harmers that are distinguishable, in part, through their reasons for self-harm. This may also be the case for individuals who harm themselves once versus repeatedly, which we did not separate in this study (Muehlenkamp, Brausch, Quigley \& Whitlock, 2013), and for individuals who self-harm only through self-poisoning. Self-poisoning is a behaviour that does not cause pain or immediate damage to the skin, and so any affective relief is less 
RUNNING HEAD: Reasons for Non-Suicidal Self-Harm in Adult Male Offenders

immediate (Brooke \& Horn, 2010). However, overdosing can serve similar affective and interpersonal functions to cutting and is sometimes performed in the absence of suicidal intent (Brooke \& Horn, 2010; Hawton, Harris \& Rodham, 2010; Rodham, Hawton, \& Evans, 2004), which justifies its inclusion in this study.

This study has implications: staff training is an integral component of the care planning system currently used in the UK prisoners at risk of self-harm or suicide (Assessment Care in Custody and Teamwork: ACCT), and our findings should be incorporated into ACCT training to improve awareness and understanding of the varied intra- and interpersonal reasons for self-harm in male offenders. As ACCT is a uniform process across the prison estate and staff implementing it often have limited or no Psychological background, an individualised approach to managing self-harm through understanding its functions may prove challenging. Policy makers must consider how the ACCT process can be responsive to these demands.

Finally, the evidence that some offenders self-harm for interpersonal reasons should not reinforce the perceived "manipulative" function of NSSH; rather, this is a genuine reason that resides within an empirically supported theoretical model of selfharm functions. Moreover, according to these results offenders hold multiple interpersonal and intrapersonal functions, thus highlighting the complexity of the reasons behind NSSH: it is performed rarely for one reason, nor one type of reason.

\section{References}

Agrawal, H. R., Gunderson, J. G., Holmes, B., \& Lyons-Ruth, K. (2004). Attachment studies with borderline patients: A review. Harvard Review of Psychiatry, 12(2), 94-104. 
RUNNING HEAD: Reasons for Non-Suicidal Self-Harm in Adult Male Offenders

American Psychiatric Association. (2013). Diagnostic and statistical manual of mental disorders: DSM-5 (5th ed.). Washington, DC: American Psychiatric Association.

Becker, D. F., Grilo, C. M., Edell, W. S., \& McGlashan, T. H. (2002). Diagnostic efficiency of borderline personality disorder criteria in hospitalized adolescents: Comparison with hospitalized adults. American Journal of Psychiatry, 159, 2042-2047. doi:10.1176/appi.ajp.159.12.2042

Bennett, A. L., \& Moss, M. (2013). Functions of deliberate self-injury of personality disordered prisoners: a small scale study. The Journal of Forensic Practice, 15(3), 171-181. doi:10.1108/JFP-08-2012-0003

Bentley, K. H., Nock, M. K., \& Barlow, D. H. (2014). The four-function model of nonsuicidal self-injury: key directions for future research. Clinical Psychological Science, 2(5), 638-656. doi:10.1177/2167702613514563

Black, D. W., Gunter, T., Allen, J., Blum, N., Arndt, S., Wenman, G. et al. (2007). Borderline personality disorder in male and female offenders newly committed to prison. Comprehensive Psychiatry, 48(5), 400-405. doi:10.1016/j.comppsych.2007.04.006

Blackburn, R., Donnelly, J. O., Logan, A., \& Renwick, S. J. (2004). Convergent and discriminative validity of interview and questionnaire measures of personality disorder in mentally disordered offenders: a multitrait-multimethod analysis using confirmatory factor analysis. Journal of Personality Disorders, 18(2), 129-150. doi: 10.1521/pedi.18.2.129.32779. Retrieved from http://ejournals.ebsco.com/direct.asp?ArticleID=4BD4BA8A97EA35D2E505 
RUNNING HEAD: Reasons for Non-Suicidal Self-Harm in Adult Male Offenders

Borrill, J., Burnett, R., Atkins, R., Miller, S., Briggs, D., Weaver, T. et al. (2003). Patterns of self-harm and attempted suicide among white and black/mixed race female prisoners. Criminal Behaviour and Mental Health, 13(4), 229-240.

Bracken-Minor, K. L., \& McDevitt-Murphy, M. E. (2014). Differences in features of non-suicidal self-injury according to borderline personality disorder screening status. Archives of Suicide Research, 18, 88-103.

doi:10.1080/13811118.2013.809040

Brain, K. L., Haines, J., \& Williams, C. L. (2002). The psychophysiology of repetitive self-mutilation. Archives of Suicide Research, 6(3), 6199-6120. doi:10.1080/13811110214140

Brooke, S., \& Horn, N. (2010). The meaning of self-injury and overdosing amongst women fulfilling the diagnostic criteria for 'borderline personality disorder'. Psychology and Psychotherapy: Theory, Research and Practice, 83, 113-128. doi:10.1348/147608309X468211

Brown, M. Z., Comtois, K. A., \& Linehan, M. M. (2002). Reasons for suicide attempts and nonsuicidal self-injury in women with borderline personality disorder. Journal of Abnormal Psychology, 111(1), 198-202.

Brunner, R., Kaess, M., Parzer, P., Fischer, G., Resch, F., Carli, V. et al. (2013). 3038Characteristics of non-suicidal self-injury and suicide attempts among adolescents in europe: results from the european research consortium seyle. European Psychiatry, 28(1), 1. 
RUNNING HEAD: Reasons for Non-Suicidal Self-Harm in Adult Male Offenders

Chandler, A., Myers, F., \& Platt, S. (2011). The construction of self-injury in the clinical literature: a sociological exploration. Suicide and Life-Threatening Behavior, 41(1), 98-109. doi:10.1111/j.1943-278X.2010.00003.x

Chapman, A. L., \& Dixon-Gordon, K. L. (2007). Emotional antecedents and consequences of deliberate self-harm and suicide attempts. Suicide and LifeThreatening Behavior, 37(5), 543-552. doi:10.1521/suli.2007.37.5.543

Claes, L., Vandereycken, W., \& Vertommen, H. (2007). Self-injury in female versus male psychiatric patients: A comparison of characteristics, psychopathology and aggression regulation. Personality and Individual Differences, 42(4), 611-621. Retrieved from http://www.sciencedirect.com/science/article/B6V9F-4M2XF991/2/e2699fd771ba5d32733b402dc0605d70

Coid, J., Yang, M., Tyrer, P., Roberts, A., \& Ullrich, S. (2006). Prevalence and correlates of personality disorder in Great Britain. The British Journal of Psychiatry, 188, 423-431.

Dear, G. E., Thomson, D. M., \& Hills, A. M. (2000). Self-harm in prison: manipulators can also be suicide attempters. Criminal Justice and Behavior, 27(2), 160-175. doi:10.1177/0093854800027002002

Dixon-Gordon, K. L., Harrison, N., \& Roesch, R. (2012). Non-suicidal self-injury within offender populations: a systematic review. International Journal of Mental Health, 11, 33-50. doi:10.1080/14999013.2012.667513

Fonagy, P., Target, M., Gergely, G., Allen, J. G., \& Bateman, A. W. (2003). The developmental roots of borderline personality disorder in early attachment relationships: a theory and some evidence. Psychoanalytic Inquiry: A Topical 
RUNNING HEAD: Reasons for Non-Suicidal Self-Harm in Adult Male Offenders

Journal for Mental Health Professionals, 23(3), 412-459.

doi:10.1080/07351692309349042

Gardner, K. J., Dodsworth, J., \& Selby, E. A. (2014). Borderline personality traits, rumination, and self-injurious behavior: An empirical test of the emotional cascades model in adult male offenders. Journal of Forensic Psychology Practice, 14(5), 398-417. doi:10.1080/15228932.2014.962379

Gardner, K., \& Qualter, P. (2009). Reliability and validity of three screening measures of Borderline Personality Disorder. Personality and Individual Differences, 46, 636-641. doi:10.1016/j.paid.2009.01.005

Groschwitz, R. C., Kaess, M., Fischer, G., Ameis, G., Schulze, U. M., Brunner, R. et al. (2015). The association of non-suicidal self-injury and suicidal behavior according to DSM-5 in adolescent psychiatric inpatients. Psychiatry Research, 228(3), 454-461. doi:10.1016/j.psychres.2015.06.019

Hamza, C. A., Stewart, S. L., \& Willoughby, T. (2012). Examining the link between nonsuicidal self-injury and suicidal behavior: A review of the literature and an integrated model. Clinical Psychology Review, 32(6), 482-495. doi:10.1016/j.cpr.2012.05.003. Retrieved from http://www.sciencedirect.com/science/article/pii/S0272735812000669

Hawton, K., Harriss, L., \& Rodham, K. (2010). How adolescents who cut themselves differ from those who take overdoses. European Child and Adolesvent Psychiatry, 19(6), 513-523. doi:10.1007/s00787-009-0065-0

Hawton, K., Lindsell, L., Adrniji, T., Sariaslan, A., Fazel, S., \& . (2014). Self-harm in prisons in England and Wales: an epidemiological study of prevalence, risk 
RUNNING HEAD: Reasons for Non-Suicidal Self-Harm in Adult Male Offenders

factors, clustering, and subsequent suicide. The Lancet, 383(9923), 1147-1154. doi:10.1016/S0140-6736(13)62118-2

Humber, N., Hayes, A., Senior, J., Fahy, T., \& Shaw, J. (2011). Identifying, monitoring and managing prisoners at risk of self-harm/suicide in England and Wales. The Journal of Forensic Psychiatry and Psychology, 22(1), 22-51. doi:10.1080/14789949.2010.518245

Hyler, S. E. (1994). Personality Diagnostic Questionnaire-4. New York: New York State Psychiatric Institute.

Jeglic, E. L., Vanderhoff, H. A., \& Donovick, P. J. (2005). The function of self-harm behavior in a forensic population. International Journal of Offender Therapy and Comparative Criminology, 49(2), 131-142.

doi:10.1177/0306624X04271130

Kapur, N., Cooper, J., King-Hele, S., Webb, R., Lawlor, M., \& Rodway, C. (2006). The repetition of suicidal behavior: a multicenter cohort study. The Journal of Clinical Psychiatry, 67(10), 1599-1609. doi: 10.4088/JCP.v67n1016

Kenning, C., Cooper, J., Short, V., Shaw, J., Abel, K., \& Chew-Graham, C. (2010). Prison staff and women prisoner's views on self-harm; their implications for service delivery and development: A qualitative study. Criminal Behaviour and Mental Health, 20(4), 278-284. doi:10.1002/cbm.777.

Kenny, D. T., Lennings, C. J., \& Munn, O. A. (2008). Risk factors for self-harm and suicide in incarcerated young offenders. Journal of Forensic Psychology Practice, 8(4), 358-382. doi:10.1080/15228930802199317 
RUNNING HEAD: Reasons for Non-Suicidal Self-Harm in Adult Male Offenders

Kleindienst, N., Bohus, M., Ludascher, P., Limberger, M. F., Kuenkele, K., EbnerPriemer, U. W. et al. (2008). Motives for nonsuicidal self-injury among women with borderline personality disorder. The Journal of Nervous and Mental Disease, 196(3), 230-236. doi:10.1097/NMD.0b013e3181663026

Klonsky, E. D., \& Olino, T. M. (2008). Identifying clinically distinct subgroups of selfinjurers among young adults: A latent class analysis. Journal of Consulting and Clinical Psychology, 76(1), 22-27.

Klonsky, E. D., \& Glenn, C. R. (2009). Assessing the functions of non-suicidal selfinjury: psychometric properties of the Inventory of Statements About Self-injury (ISAS). Journal of Psychopathology and Behavioral Assessment, 31, 215-219.

Klonsky, E. D., May, A. M., \& Glenn, C. R. (2013). The relationship between nonsuicidal self-injury and attempted suicide: converging evidence from four samples. Journal of Abnormal Psychology, 112(1), 231-237. doi: $10.1037 / \mathrm{a} 0030278$

Klonsky, E. D. (2007). The functions of deliberate self-injury: A review of the evidence. Clinical Psychology Review, 27(2), 226-239. Retrieved from http://www.sciencedirect.com/science/article/B6VB8-4M1D0C41/2/1759cc3e9d3f38ccb564dc4e07030498

Klonsky, E. D. (2009). The functions of self-injury in young adults who cut themselves: Clarifying the evidence for affect-regulation. Psychiatry Research, 166(2-3), 260-268. Retrieved from http://www.sciencedirect.com/science/article/B6TBV4VT5CG0-4/2/f42eee024feaf403931b4ccfdcdf50c0 
RUNNING HEAD: Reasons for Non-Suicidal Self-Harm in Adult Male Offenders

Knowles, S., Townsend, E., \& Anderson, M. (2011). Factors associated with self-harm in community-based young offenders: the importance of psychological variables. The Journal of Forensic Psychiatry and Psychology, 22(4), 479-495. doi:10.1080/14789949.2011.591415

Knowles, S., Townsend, E., \& Anderson, M. P. (2013). 'In two minds'--socially motivated self-harm is perceived as less serious than internally motivated: a qualitative study of youth justice staff. Journal of Health Psychology, 18(9), 1187-1198. doi:10.1177/1359105312459874

Linehan, M. (1993). Cognitive-behavioral treatment of borderline personality disorder. New York: The Guildford Press.

Lohner, J., \& Konrad, N. (2006). Deliberate self-harm and suicide attempt in custody: Distinguishing features in male inmates' self-injurious behavior. International Journal of Law and Psychiatry, 29(5), 370-385. doi:10.1016/j.ijlp.2006.03.004. Retrieved from http://www.sciencedirect.com/science/article/pii/S0160252706000471

Lohner, J., \& Konrad, N. (2007). Risk factors for self-injurious behaviour in custody: Problems of definition and prediction. International Journal of Prisoner Health, 3(2), 135-161. doi:10.1080/17449200701321654

Maden, A., Chamberlain, S., \& Gunn, J. (2000). Deliberate self-harm in sentenced male prisoners in England and Wales: some ethnic factors. Criminal Behaviour and Mental Health, 10(3), 199-204. doi:10.1002/cbm.357 
RUNNING HEAD: Reasons for Non-Suicidal Self-Harm in Adult Male Offenders

Mannion, A. (2009). Self-harm in a dangerous and severely personality disordered population. The Journal of Forensic Psychiatry and Psychology, 20(2), 322-331. doi:10.1080/14789940802377106

Mars, B., Heron, J., Crane, C., Hawton, K., Kidger, J., Lewis, G. et al. (2014).

Differences in risk factors for self-harm with and without suicidal intent: findings from the ALSPAC cohort. Journal of Affective Disorders, 168, 407414. doi:10.1016/j.jad.2014.07.009

Marzano, L., Ciclitira, K., \& Adler, J. (2012). The impact of prison staff responses on self-harming behaviours: Prisoners' perspectives. British Journal of Clinical Psychology, 51(1), 4-18. doi: 10.1111/j.2044-8260.2010.02007.x

Marzano, L., Adler, J. P., \& Ciclitira, K. (2013). Responding to repetitive, non-suicidal self-harm in an English male prison: Staff experiences, reactions, and concerns. Legal and Criminological Psychology. doi:10.1111/lcrp.12025

Miller, G. A., \& Chapman, J. P. (2007). Misunderstanding of analysis of covariance. Journal of Abnormal Psychology, 110, 40-48. doi:10.1037//0021-843X.110.1.40

Ministry of Justice. (2015). Ministry of Justice Statistics Bulletin. Safety in custody statistics: England and Wales (December 2014).

Muehlenkamp, J., Brausch, A., Quigley, K., \& Whitlock, J. (2013). Interpersonal features and functions of nonsuicidal self-injury. Suicide and Life-Threatening Behavior, 43(1), 67-80. doi:10.1111/j.1943-278X.2012.00128.x 
RUNNING HEAD: Reasons for Non-Suicidal Self-Harm in Adult Male Offenders

Nock, M. K. (2008). Actions speak louder than words: An elaborated theoretical model of the social functions of self-injury and other harmful behaviors. Applied and Preventive Psychology, 12, 159-168.

Nock, M. K. (2010). Self-injury. Annual Review of Clinical Psychology, 6, 339-363. doi:10.1146/annurev.clinpsy.121208.131258.

Nock, M. K., \& Prinstein, M. J. (2004). A Functional Approach to the Assessment of Self-Mutilative Behavior. Journal of Consulting and Clinical Psychology, 72(5), 885-890.

Nock, M. K., \& Prinstein, M. J. (2005). Contextual features and behavioral functions of self-mutilation among adolescents. Journal of Abnormal Psychology, 114(1), 140-146.

Osman, A., Bagge, C. L., Gutierrez, P. M., Konick, L. C., Kopper, B. A., \& Barios, F. X. (2001). The Suicidal Behaviors Questionnaire-Revised (SBQ-R): validation with clinical and nonclinical samples. Assessment, 8(4), 443-454.

Pannell, J., Howells, K., \& Day, A. (2003). Prison officer's beliefs regarding self-harm in prisoners: an empirical investigation. International Journal of Forensic Psychology, 1(1), 103-110.

Penn, J., Esposito, C. L., Schaeffer, L. E., Fritz, G. K., \& Spirito, A. (2003). Suicide attempts and self-mutilative behavior in a juvenile correctional facility. Journal of the American Academy of Child and Adolescent Psychiatry, 42(7), 762-769. doi:10.1097/01.CHI.0000046869.56865.46 
RUNNING HEAD: Reasons for Non-Suicidal Self-Harm in Adult Male Offenders

Radolff, L. S. (1977). The CES-D Scale: A self-report depression scale for research in the general population. Applied Psychological Measurement, 1(3), 385-401. doi:10.1177/014662167700100306

Rodham, K., Hawton, K., \& Evans, E. (2004). Reasons for deliberate self-harm: Comparison of self-poisoners and self-cutters in a community sample of adolescents. Journal of the American Academy of Child and Adolescent Psychiatry, 43, 80-87.

Sadeh, N., Londahl-Shaller, E. A., Piatigorsky, A., Fordwood, S., Stuart, B. K., McNiel, D. E. et al. (2014). Functions of non-suicidal self-injury in adolescents and young adults with Borderline Personality Disorder symptoms. Psychiatry Research, 216(2), 217-222. doi:10.1016/j.psychres.2014.02.018. Retrieved from http://www.sciencedirect.com/science/article/pii/S016517811400136X

Sansone, R. A., \& Sansone, L. A. (2009). Borderline personality and criminality. Psychiatry, 6(10), 16-20.

Saraff, P. D., \& Pepper, C. M. (2014). Functions, lifetime frequency, and variety of methods of non-suicidal self-injury among college students. Psychiatry Research, 219(2), 298-304. doi:10.1016/j.psychres.2014.05.044. Retrieved from http://www.sciencedirect.com/science/article/pii/S0165178114004600

Scoliers, G., Portzky, G., Madge, N., Hewitt, A., Hawton, K., de Wilde, E. J. et al. (2009). Reasons for adolescent deliberate self-harm: a cry of pain and/or a cry of help? Findings from the child and adolesvent self-harm in Europe (CASE) study. Social Psychiatry and Psychiatric Epidemiology, 44(8), 601-607. doi:10.1007/s00127-008-0469-z 
RUNNING HEAD: Reasons for Non-Suicidal Self-Harm in Adult Male Offenders

Vollm, B., \& Dolan, M. C. (2009). Self-harm among UK female prisoners: a crosssectional study. The Journal of Forensic Psychiatry and Psychology, 20(5), 741751. doi:10.1080/14789940903174030

Zanarini, M., Horwood, J., Wolke, D., Waylen, A., Fitzmaurice, G., \& Grant, B. F. (2011). Prevalence of DSM-IV borderline personality disorder in two community samples: 6,330 English 11-year-olds and 34,653 American adults. Journal of Personality Disorders, 25(5), 607-619.

\section{Footnotes}

1. This method assumes that per episode participants used one method. Participants could have used multiple methods within one episode. 
RUNNING HEAD: Reasons for Non-Suicidal Self-Harm in Adult Male Offenders

\section{Table 1:}

Prison and Psychological Characteristics of NSSH and Non-NSSH Offenders

\begin{tabular}{|c|c|c|c|}
\hline & No NSSH $(n=137)$ & $\operatorname{NSSH}(n=42)$ & Significance \\
\hline Self-Reported time spent on self- & 12.5 & 51.2 & $\chi^{2}(1)=28.01, p<.001^{1}$ \\
\hline \multicolumn{4}{|l|}{ harm/suicide monitoring (\%) } \\
\hline Meets threshold for BPD (\%) & 8.8 & 47.6 & $\chi^{2}(1)=33.06, p<.001^{1}$ \\
\hline Meets threshold for APD (\%) & 22.5 & 50.0 & $\chi^{2}(1)=8.94, p<.001^{1}$ \\
\hline Meets threshold for HPD (\%) & 0.7 & 4.8 & $\chi^{2}(1)=3.17$, Fisher's exact $p=.138^{2}$ \\
\hline Meets threshold for NPD (\%) & 6.6 & 14.3 & $\chi^{2}(1)=2.49$, Fisher's exact $p=.122^{2}$ \\
\hline Depression (M [SD]) & $17.07(8.45)$ & $24.83(9.52)$ & $t(177)=-5.06, p<.001^{3}$ \\
\hline Suicidal Behaviours (M [SD]) & $4.27(1.96)$ & $6.89(3.00)$ & $t(52.14)=-5.33, p<.001^{3}$ \\
\hline
\end{tabular}

${ }^{1} p$ value obtained from Pearson chi square test. ${ }^{2} p$ value obtained from Fisher's exact test due to low expected cell frequencies. ${ }^{3} \mathrm{p}$ value obtained from independent samples t-tests. 
RUNNING HEAD: Reasons for Non-Suicidal Self-Harm in Adult Male Offenders

Table 2:

Percentage of offenders using different NSSH methods and frequency of NSSH

\begin{tabular}{|c|c|c|c|}
\hline & $\begin{array}{l}\text { NSSH sample (\%) } \\
\qquad(\mathrm{n}=42)\end{array}$ & $\begin{array}{l}\text { NSSH sample with Low } \\
\text { BPD traits }(\%)(n=22)\end{array}$ & $\begin{array}{l}\text { NSSH sample with high } \\
\text { BPD traits }(\%)(\mathrm{n}=\mathbf{2 0})\end{array}$ \\
\hline \multicolumn{4}{|l|}{ Method } \\
\hline Banging or hitting self & 33.3 & 9.1 & $60.0 * * *$ \\
\hline Hair pulling & 9.5 & 4.5 & 15.0 \\
\hline Pinching & 11.9 & 4.5 & 20.0 \\
\hline Cutting & 59.5 & 45.5 & 75.0 \\
\hline Biting & 16.7 & 4.5 & $30.0^{*}$ \\
\hline Wound picking & 33.3 & 13.6 & $55.0^{* *}$ \\
\hline Severe scratching & 23.8 & 18.2 & 30.0 \\
\hline Rubbing skin against rough surfaces & 11.9 & 0.0 & $25.0 *$ \\
\hline Burning & 19.0 & 13.6 & 25.0 \\
\hline Needle sticking & 4.8 & 4.5 & 5.0 \\
\hline Carving & 16.7 & 4.5 & $30.0 *$ \\
\hline Swallowing dangerous substances & 31.0 & 13.6 & $50.0 *$ \\
\hline Other & 19.0 & 9.1 & 30.0 \\
\hline \multicolumn{4}{|c|}{ Frequency of NSSH incidents across all methods } \\
\hline Range & $1-4000$ & $1-180$ & $2-4000$ \\
\hline Median & 8.5 & 2.5 & 214.0 \\
\hline Mode & 1.0 & 1.0 & 4 \\
\hline
\end{tabular}

Note: Statistical significance determined by Mann Whitney U test. $* p<.05, * * p<.01, * * * p<.001$ 
RUNNING HEAD: Reasons for Non-Suicidal Self-Harm in Adult Male Offenders

Table 3

Means (M), Standard Deviations (SD), Reliability and Correlations of ISAS Functions

\begin{tabular}{|c|c|c|c|}
\hline & & & $\begin{array}{c}\text { Klonsky \& Glenn } \\
\text { (2009) }\end{array}$ \\
\hline Function & Reliability & $M(S D)$ & $M(S D)$ \\
\hline \multicolumn{4}{|l|}{ 1. Intrapersonal } \\
\hline 2. Affect regulation & .67 & $2.60(2.23)$ & $3.0(2.1$ \\
\hline 3. Anti-dissociation & .77 & $1.53(1.99)$ & $1.0(1.6)$ \\
\hline 4. Anti-suicide & .85 & $1.43(1.20)^{* *}$ & $0.8(1.4)$ \\
\hline 5. Marking distress & .85 & $1.15(1.89)$ & $1.4(1.8)$ \\
\hline 6. Self-punishment & .86 & $2.75(2.34)$ & $2.0(2.1)$ \\
\hline 7. Autonomy & .66 & $.69(1.34)$ & $0.6(1.3)$ \\
\hline \multicolumn{4}{|l|}{ 8. Interpersonal } \\
\hline 9. Interpersonal boundaries & .77 & $.90(1.35)$ & $0.8(1.4)$ \\
\hline 10. Interpersonal Influence & .54 & $1.10(1.50)$ & $0.8(1.4)$ \\
\hline 11. Peer bonding & .60 & - & $0.5(1.3)$ \\
\hline 12. Revenge & .77 & - & $0.6(1.4)$ \\
\hline 13. Self-care & .76 & $.77(1.51)$ & $0.8(1.4)$ \\
\hline 14. Sensation seeking & .88 & - & $0.7(1.3)$ \\
\hline 15. Toughness & .69 & $.95(1.55)$ & $1.0(1.4)$ \\
\hline
\end{tabular}

Note: Mean not calculated for Peer Bonding, Revenge and Sensation Seeking due to insufficient variability in the data; all three variables contained excess zeros and only several extreme univariate outliers. Mean scores were compared to those in a previously published student sample (Klonsky \& Glenn, 2009) and the WelchSatterthwaite test for independent samples with unequal variances was used to calculate significance.

$* p<.05 . * * p<.01, * * * p<.001$ 
RUNNING HEAD: Reasons for Non-Suicidal Self-Harm in Adult Male Offenders

Table 4:

Frequency (\%) of NSSH Sample and Individuals with Low and High BPD Traits Endorsing Each Reason

\begin{tabular}{|c|c|c|c|c|c|}
\hline Reasons for NSSH & $\begin{array}{c}\text { Total NSSH } \\
\text { sample }(n=42)\end{array}$ & $\begin{array}{c}\text { Low BPD } \\
(n=22)\end{array}$ & $\begin{array}{c}\text { High BPD } \\
(\mathbf{n}=\mathbf{2 0})\end{array}$ & Low vs. High BPD $\chi^{2}(p)$ & $\begin{array}{c}\text { Effect size: } \\
\text { Phi }(\varphi)\end{array}$ \\
\hline \multicolumn{6}{|l|}{ Intrapersonal domain (15 reasons) } \\
\hline (1)...calming myself down & 41.0 & 30.0 & 52.6 & .151 & .23 \\
\hline $\begin{array}{l}\text { (14)... releasing emotional pressure that has built up inside } \\
\text { of me }\end{array}$ & 65.0 & 45.0 & 85.0 & $.008 * *$ & .42 \\
\hline \multicolumn{6}{|l|}{ overwhelming emotions } \\
\hline \multicolumn{6}{|l|}{ Anti-Dissociation } \\
\hline (5)...causing pain so I will stop feeling numb & 46.2 & 20.0 & 73.7 & $.001 * * *$ & .54 \\
\hline $\begin{array}{l}\text { (18)...trying to feel something (as opposed to nothing) even } \\
\text { if it is physical }\end{array}$ & 30.0 & 14.3 & 47.4 & $.038 *$ & .36 \\
\hline (6).... avoiding the impulse to attempt suicide & 25.6 & 5.0 & 47.7 & $.003 * * 1$ & .49 \\
\hline $\begin{array}{l}\text { (19)... responding to suicidal thoughts without actually } \\
\text { attempting suicide }\end{array}$ & 37.5 & 15.0 & 60.0 & $.008 * *$ & .47 \\
\hline (32)...putting a stop to suicidal thoughts & 28.9 & 10.5 & 47.4 & $.012 *$ & .41 \\
\hline
\end{tabular}




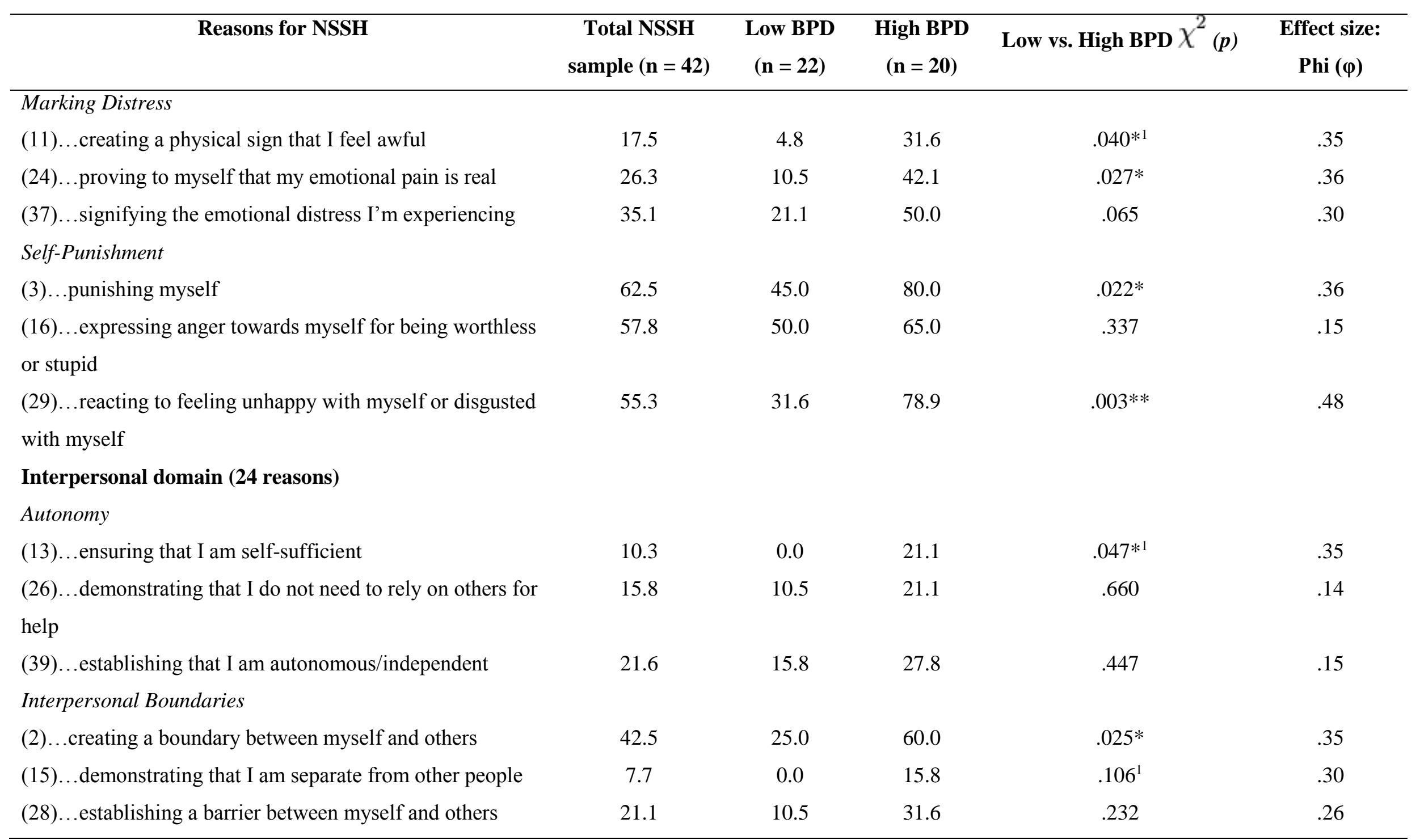




\begin{tabular}{|c|c|c|c|c|c|}
\hline Reasons for NSSH & $\begin{array}{c}\text { Total NSSH } \\
\text { sample }(n=42)\end{array}$ & $\begin{array}{c}\text { Low BPD } \\
(\mathrm{n}=22)\end{array}$ & $\begin{array}{l}\text { High BPD } \\
(\mathbf{n}=\mathbf{2 0})\end{array}$ & Low vs. High BPD $\chi^{2}(p)$ & $\begin{array}{c}\text { Effect size: } \\
\text { Phi }(\varphi)\end{array}$ \\
\hline \multicolumn{6}{|l|}{ Interpersonal Influence } \\
\hline (22)... seeking care or help from others & 23.7 & 10.5 & 36.8 & $.124^{1}$ & .31 \\
\hline (35)...keeping a loved one from leaving or abandoning me & 21.1 & 10.5 & 31.6 & $.232^{1}$ & .26 \\
\hline (21)...fitting in with others & 2.7 & 0.0 & 5.3 & $1.00^{1}$ & .16 \\
\hline $\begin{array}{l}\text { (34)...creating a sign of friendship or kinship with friends } \\
\text { or loved ones }\end{array}$ & 5.3 & 0.0 & 10.5 & $.486^{1}$ & .24 \\
\hline \multicolumn{6}{|l|}{ Revenge } \\
\hline \multicolumn{6}{|l|}{ Self-Care } \\
\hline $\begin{array}{l}\text { (4)...giving myself a way to care for myself (by attending } \\
\text { to the wound) }\end{array}$ & 17.9 & 5.0 & 31.6 & $.044 * 1$ & .35 \\
\hline $\begin{array}{l}\text { (17)...creating a physical injury that is easier to care for } \\
\text { than my emotional distress... }\end{array}$ & 25.6 & 20.0 & 31.6 & $.480^{1}$ & .13 \\
\hline $\begin{array}{l}\text { (30)...allowing myself to focus on treating the injury, } \\
\text { which can be gratifying or satisfying }\end{array}$ & 5.3 & 0.0 & 10.5 & $.486^{1}$ & .24 \\
\hline
\end{tabular}


RUNNING HEAD: Reasons for Non-Suicidal Self-Harm in Adult Male Offenders

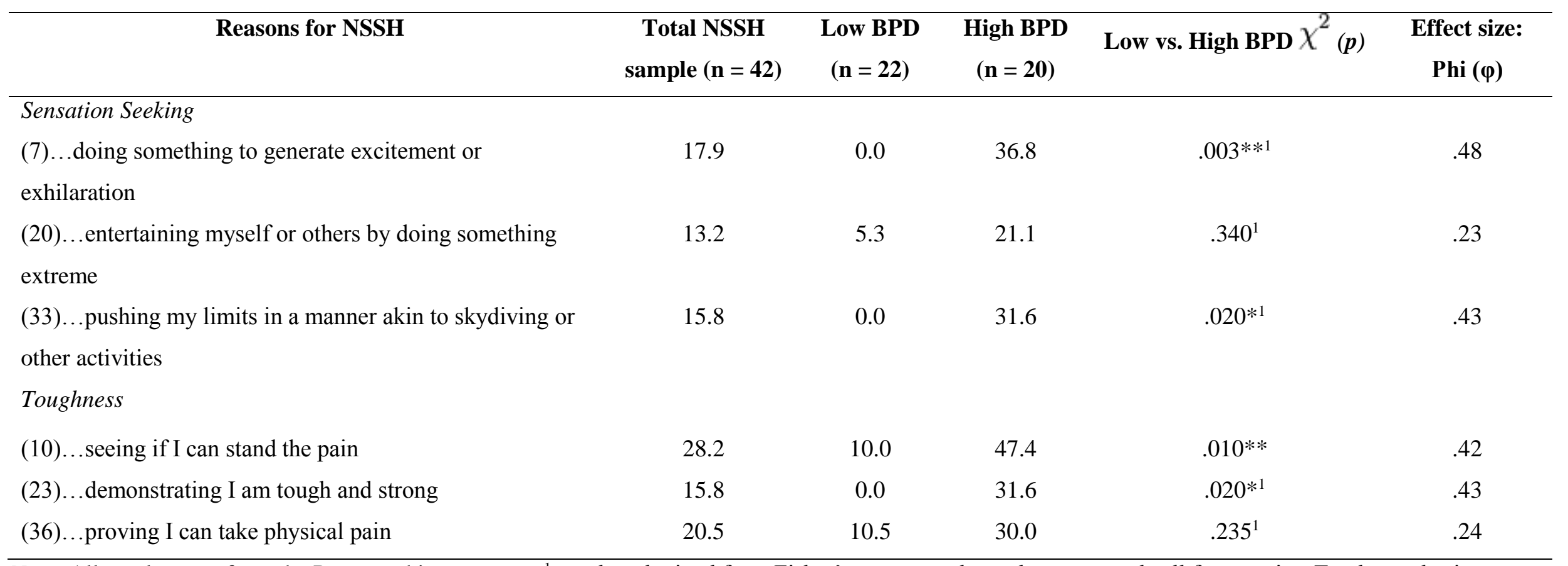

Note: All $p$ values are from the Pearson chi square test. ${ }^{1} p$ value obtained from Fisher's exact test due to low expected cell frequencies. Total sample size ranges from 37 to 42 due missing data for some functions.

$* p<.05 . * * p<.01, * * * p<.001$ 